\title{
The Last Stop
}

\author{
Preston A. Britner
}

Published online: 25 November 2009

(C) Springer Science+Business Media, LLC 2009

This is the final issue of the year and my tenure as Editor of The Journal of Primary Prevention. In this editorial, I preview six research articles and a tribute to one of the pioneers of primary prevention, Don Klein, and then conclude with thanks to the many friends and colleagues who have supported my work with JPP.

\section{Research Articles in This Issue}

This issue contains six empirical papers (five articles and a Report from the Field) related to strategies and programs to prevent substance use, violence, sexual risk talking, and sexual assault among adolescents, youth, and emerging adults.

Lopez et al. present findings from a study of family, school, and peer factors as they inter-relate to the likelihood of substance use in a sample of Hispanic adolescents in Miami. This research is promising both in terms of the implications for targets of prevention programming and for the application of ecodevelopmental theory, which might guide similar efforts with different cultural groups.

Jagers and colleagues build on prior research on the Aban Aya Youth Project by comparing social development classroom curriculum, school/family/community intervention curriculum, and a health enhancement curriculum attention placebo control conditions on changes over time in violent behaviors among participating youth. Using grade 5 pretest and grades 5-8 posttest data, as well as information about youth who joined the study after baseline, to investigate the possibility of differential intervention effects. The authors present promising violence prevention findings, and they also provide important answers to dosage and developmental timing questions with their analyses of these longitudinal data.

\section{P. A. Britner $(\bowtie)$}

Human Development \& Family Studies, University of Connecticut, U-2058, Storrs, CT 06269-2058, USA

e-mail: Preston.Britner@UConn.edu 
Carmack and Lewis-Moss studied African American adolescents participating in risk reduction classes; adolescents were assessed on their initial attitudes, norms, perceived control, and intention regarding condom use. Comparing models within the Theory of Planned Behavior (TPB), second-order structural equation modeling indicated that the effect-indicator model exhibited superior fit above the causalindicator model. Despite limitations including correlational data, this study yields implications for prevention programming and, more broadly, an important theoretical elaboration on effect-indicator and causal-indicator models of the TPB.

Using data from the National Longitudinal Survey of Youth, Brookmeyer and Henrich studied pathways of risk within sexual risk taking, alcohol use, and delinquency, and then how the trajectory of sexual risk is linked to alcohol use and delinquency. Latent Class Growth Analyses models indicated that the majority of adolescents engaged in sexual risk and alcohol use. School administrators and curriculum designers should pay attention to the study's findings with respect to the need for prevention programs to target early adolescents and integrate prevention messages about alcohol use and sexual risk taking.

Bradley et al. evaluated the short-term effectiveness of a mixed-gender sexual assault prevention program for college students. The prevention program was effective at increasing men's victim empathy and decreasing their adherence to rape myths but ineffective at changing women's assault-related knowledge, participation in risky dating behaviors, and sexual communication strategies (in the short term). This study provides an important example of the limitations of a single session prevention programming approach (even if it is well designed and executed) in addressing a systemic and pervasive problem like sexual assault on college campuses.

In a Report from the Field, O'Grady and colleagues present preliminary findings from a brief, peer-led safer sex intervention-based on the Information-MotivationBehavioral Skills theoretical model-for college students in residential halls. Compared to the single session control condition, the five module intervention increased participants' information and women's subjective norms about preventive behavior.

\section{Celebrating Don Klein}

Following the empirical articles in the issue is a distinctly qualitative tribute to Donald C. Klein, a pioneer in primary prevention who passed away in 2007. We remember and celebrate his life and work with the thoughts and reflections of colleagues, family, and friends. I believe that these words about how Don respected others, worked for equality and human dignity, and lived his life to the fullest will bring a smile to those who knew him and serve as an inspiration to those who weren't so lucky.

\section{Thank You}

As I have done each year, I end this last issue of the volume with my personal thanks to the reviewers and Editorial Board members whose efforts are so crucial to 
the workings of the journal. Because this is the end of my 5 years at the helm, I need to add some special thanks. Many of the members of the Editorial Board have served-and served well-for a very long time, and their experience and commitment to $J P P$ is appreciated. Paul Brounstein and Alice Sterling Honig have been $J P P$ 's Associate Editors for the last 5 years, and their expertise-especially on substance use and early childhood papers, respectively-was most helpful to me. More recently, Ken McLeroy accepted my invitation to become the third Associate Editor, and he contributed right away. I thank each of you.

On a day-to-day basis, my Editorial Assistants, Lily Alpert (2005-2007) and Sara Johnson (2007-2009) were instrumental in every step of the editorial process. As doctoral students in Human Development and Family Studies at the University of Connecticut, they brought skill and talent to the position and learned a great deal from their experiences in the role. Lily, Ph.D. in hand, has gone onto great things (SRCD Congressional Fellowship, then a research/policy analyst position with Children's Rights, Inc.). Sara continues her impressive research as a doctoral student at UConn, and her academic future is bright. These are two of the smartest, most committed, and most helpful people that I know. I can't even begin to thank each of them enough for the work they did for me and for the journal.

I want to acknowledge: the University of Connecticut and the Department of Human Development and Family Studies for the support of my editorial office; my friends and colleagues at UConn and around the world who responded to my pleas to review papers; the Guest Editors who worked with me to craft some interesting and influential special issues; Editor Emeritus (and friend and mentor) Martin Bloom for bringing me on as his Associate Editor in 2003 and his successor as Editor in 2005; and, my wife and children for tolerating my poor work/family boundary skills.

Lastly, I thank all of the many people at Springer (but especially Bill Tucker, Executive Editor for Health and Behavior, and Khristine Queja, JPP's Publishing Editor and Editor for Health and Behavior) who have supported the efforts of the Editors and Editorial Board to make The Journal of Primary Prevention such a strong publication outlet and resource for prevention researchers and practitioners, worldwide and across disciplinary boundaries. I can "retire" from this position knowing that JPP is in good shape and is now in the capable hands of Susan Tortolero, who is the Director of the University of Texas Prevention Research Center, an Epidemiology faculty member at the UT Houston School of Public Health, and an accomplished researcher in areas including children's mental health and chronic disease prevention, adolescent behavioral risk factors, and physical activity in minority women. Along with the team from Springer and our respective Editorial Assistants, we have been working together over the last several months to guarantee a smooth transition. Susan will bring her own expertise and ideas about the direction of the journal to build upon the work of the previous three editors. I know that you will all join me in welcoming her and assisting her with the important business of the design, study, and promotion of primary prevention efforts to improve our world. 